\title{
Translating Science for Young People through Metaphor ${ }^{1}$
}

\author{
Alice Deignan (Leeds University) and Elena Semino (Lancaster University)
}

In this article we show what insights can be gained by considering the relationship between expert and non-expert texts about scientific topics through the lens of 'translation'. We focus specifically on the metaphors used to discuss climate change in a range of educational materials and in interviews with secondary school students in the UK. We show the complex web of relationships among the people and genres that may influence students' understandings of climate change, and focus on the role of teachers in particular as 'translators' of scientific knowledge. We then report on several comparisons of metaphor use among texts and genres that stand in source-target relationships within this web of intralingual translations, and also consider the metaphors used by students themselves to express their understanding of climate change. We conclude by reflecting on the implications of the differences we have observed, and suggest that a translation perspective can usefully highlight the challenges and potential pitfalls involved in mediating scientific knowledge for the benefit of non-experts such as school-age students.

\section{Introduction}

Scientific research is rarely understandable to non-scientists in the form in which it is published to peers. Writers of popular science and science educational materials have the task of taking this expert knowledge and re-presenting it in an accessible form to novice readers and speakers. There is interest in the scientific community in how this task can be carried out most successfully, because of the concern to enable the public to contribute knowledgeably to debate and to make informed decisions. (Lombardi et al. 2016; Tasquier, Levrini, and Dillon 2016). In the case of climate change, the issue is particularly pressing, because the future of, at very least, current ways of life, and at worst, humanity itself are at stake. As extreme climate change is likely to manifest towards the second half of the $21^{\text {st }}$ century onwards, communication with young people is especially important.

Our research has considered this process, with a specific focus on metaphor and secondary school students in the UK, using texts and corpora of texts produced by and for different groups on the topic of climate change. The rationale for this focus is three-fold: (1) the widely recognised importance of metaphor in science and education (Brown 2003; Cameron 2003; Deignan, Littlemore, and Semino 2013); (2) the increasing concentrations of $\mathrm{CO}_{2}$ in the atmosphere, and growing evidence of warming caused by human activities (NASA: https://climate.nasa.gov); and (3) changes to the England and Wales National Curriculum ${ }^{2}$ regarding climate change in 2013-14 (e.g. Hicks, Ward, and Lester 2013).

Specifically, our project set out to answer the following research questions:

\footnotetext{
${ }^{1}$ This is part of a larger study funded by AHRC grant number AH/M003809/1

2 The National Curriculum states in considerable detail the topics that must be covered in government schools. All subjects are compulsory until students are in their early teens.
} 
1. What are the networks of 'translation' of scientific knowledge between experts, educators and young people?

2. How do metaphors and similes mediate the translation of scientific knowledge across groups of texts intended for different readerships or audiences?

3. How are metaphors and similes used and changed as knowledge is translated by and for different groups?

In this article we begin by briefly discussing the most relevant literature on translation, science and metaphor. We then describe our data, and comment on what they show about the relationships between different text types on the topic of climate change. We then present three comparative linguistic analyses of metaphor use across texts and genres, and consider what these show about the intralingual translation of science for non-scientists, especially school students.

\section{Translation, science and metaphor}

As Liao (2011) points out, translators of scientific texts play an important, and not often acknowledged, role in 'mediating the interaction between source texts and target readers' (2011: 365). However, the focus in Translation Studies has so far been primarily on the translation of expert and technical scientific texts (e.g. Krein-Kühle 2011), rather than on texts from popular science and science education. This is in spite of the fact that the latter types of texts tend to reach wider audiences. In addition, the relationship between specialist and popular/educational texts about science has not so far been approached as a case of intralingual translation, but primarily from the perspective of the 'recontextualisation' of scientific knowledge across texts and genres (Semino, Deignan, and Littlemore 2013, Pramling and Säljö 2007, Incelli 2018). Applying a translation perspective to our data involves a focus on the agents, processes and products of textual choices that is particularly appropriate to addressing our research questions.

With regards to metaphor, a substantial literature exists on interlingual translation, as part of a line of work that is often traced back to Newmark's (1988) seminal study. Typologies of translation strategies for metaphor tend to share a common core (e.g. Toury 1995; Kövecses 2005; Al-Hasnawi 2007; and Schäffner 2017 for a summary):

- The translation of a metaphor in the source text with a metaphor in the target text that is drawn from the same area of experience or, in terms of Conceptual Metaphor Theory, 'source domain' (Lakoff and Johnson 1980);

- The translation of a metaphor in the source text with a metaphor in the target text that is drawn from a different area of experience or source domain;

- The translation of a metaphor in the source text with non-metaphorical language in the target text.

In addition to including other potential strategies (e.g. glossing a source text metaphor or turning it into a simile), studies of the interlingual translation of metaphor often emphasize that 'cultural' factors can be a challenge for translators, and sometimes recognise the influence of 'genre conventions (as found by Rodríguez Márquez 2010), time constraints, institutional arrangements, or other factors' (Schäffner 2017: 253). Indeed, metaphor scholars have recently provided substantial evidence of variation in metaphor use across 
genres, registers and 'discourse communities', involving the frequencies, forms and/or functions of metaphorical expressions and related figurative uses of language, such as similes (Steen et al. 2010; Deignan et al. 2013; Swales 1990; Barton 2007).

Deignan et al. (2013) consider both genre and register in exploring differences in figurative language use. In their framework, 'genre' is comprised of three variables: discourse community, purpose and staging. The text types that we study in the present paper differ across all three, but here we are more specifically interested in the first two. Our text types belong to different discourse communities, from teachers to school students of different ages. The educational texts and websites that we analyse are written by insiders to help outsiders to join the discourse community. Purpose is closely related to discourse community, and also differentiates between the different groups of text types that we analysed, which include educational, informative, entertainment and persuasion. We therefore consider our different text types to represent different genres on the same topic.

Metaphor makes it possible to talk and think about one thing in terms of another, such as the structure of atoms in terms of the solar system (Brown 2003) and DNA in terms of a code of instructions (Knudsen 2005; Pramling and Säljö 2007). As such, metaphor is well known to play an often central role in the development of scientific theories, as well as in the explanation of scientific concepts for the benefit of non-experts, including in educational contexts (Brown 2003, Knudsen 2003, Christidou et al 2004). In spite of this, very little work exists on metaphor in scientific translation. An exception is Shuttleworth (2011), who analysed over 1300 metaphors from Scientific American articles and their translations in five different European languages. Among other things, Shuttleworth uses his findings to highlight the contrast between the concern for 'universal' aspects of metaphor use in Conceptual Metaphor Theory (based on the notion of embodiment) and the emphasis on linguistic and cultural variation in Translation Studies. The patterns identified by Shuttleworth are in fact consistent with the findings of the research on metaphor in discourse mentioned above.

In this paper we bring together these different lines of research by looking at metaphors used in specialist, popular and educational genres. As their topic, climate change, is constant, and there is a pattern of dependence between the genres, explored below, we treat the relationships between the genres as cases of intralingual translation.

\section{Data}

As part of the project, 'Translating science for young people', we gathered various datasets relating to the communication of scientific knowledge about climate change. These included interviews involving nine secondary school teachers at four different secondary schools in the north of England, which took place in 2015 (for a total of 32,283 words of transcription). The schools were alike in that they were all state (public, not fee-paying), comprehensive (non-selective), but different in their contexts, ranging through inner-city, suburban to small town and rural contexts, with corresponding variation in the students' socio-economic and educational backgrounds. The interview questions focussed on teaching climate science to students aged 11-16, that is from the beginning of secondary education, through the years in which science is a compulsory subject. Among other things, teachers were asked about 
the sources and materials they use as part of their professional practice, including books, journals, websites, etc.

We also interviewed students, in 41 groups of between four and six students per group, from the same four schools (for a total of 87,888 words of transcription). Students were asked to articulate their knowledge about climate change, and, as with teachers, they were asked to mention any sources or materials they use, or would consider using, to develop that knowledge.

Finally, we built several corpora of written texts, three of which will be analysed in this paper, alongside the corpora of interviews with teachers and students:

1. 'Teacher sources' corpus - 18 extracts from books and websites (including the websites of popular science publications) that the teachers we interviewed said they consulted to improve their own knowledge of climate change (53,626 words).

2. 'Textbooks' corpus -26 extracts about climate change from textbooks used in UK schools to teach science and geography to students aged 11-16 (21,954 words).

3. 'Websites' corpus - Websites that the school students we interviewed said they would be likely to refer to $(188,232$ words).

In the next three sections, we present three analyses involving these different corpora. Discussions of the additional corpora we built as part of our project (e.g. corpora consisting of academic articles and policy documents about climate change) can be found in Deignan (2017) and Deignan, Semino and Paul (2017).

\section{Analysis 1: Relationships between climate change text types}

Our first research question concerns networks of 'translation' of scientific knowledge between experts, educators and young people. To answer this question, we analysed the teachers' and students' interview responses, traced source attribution in the texts in our various corpora, and consulted the literature on educational texts.

All secondary school science teachers in England have Bachelors' degrees in a science subject, but it was immediately apparent that the teachers rarely or never consult scientific texts written for scientists, such as peer reviewed journals. In total, they listed 15 books and 3 websites. Of the books, 11 are textbooks for older school students, studying A Level Biology. ${ }^{3}$ They also listed some teacher packs; neither these, nor the textbooks, gave sources. Publishers give relatively little information about authors, but, where this is available, it indicates that authors of textbooks tend to be expert teachers rather than scientists. Source information is largely based on the National Curriculum for England and Wales and examination specifications, which are also, in turn, based on the National Curriculum. DiGiuseppe (2014) studied the relationship between editors, authors and publishers of science textbooks in North America and came to the same conclusion.

\footnotetext{
3 In England, the more academically able of 16-18 year olds take quite specialised courses leading to 'A Levels'.
} 
The National Curriculum is in the public domain, but it does not cite its sources directly. It states that pupils need to acquire 'knowledge', variously described as 'core', 'essential' and, in the science curriculum, 'scientific', implying that this is both widely shared among education professionals, and undisputed. The most explicit statement of sources that we were able to find among recent Department for Education (DfE) publications comes in a DfE proposal for the reforms to the National Curriculum which were to be enacted in 2014:

We have worked with subject experts and key organisations across all National Curriculum subjects to inform our thinking [...] In June 2012, we published draft programmes of study for primary English, mathematics and science for wider discussion. Since then, we have discussed the drafts with key subject organisations, teachers and subject experts, and have reviewed the content in the light of the helpful feedback we received. (Department for Education, 2013)

This proposal invited comments. Responses to the proposed reforms from various organisations are publicly available, evidencing considerable discussion around how climate change was to be presented and taught. For example, the Grantham Institute, a research centre based at the London School of Economics, produced a detailed and strongly worded response, including the following:

Under the proposed new Framework for the programmes of study, the core knowledge of pupils aged under 14 about climate change would be significantly diminished. No references are made to the key topics of climate impacts, sustainability and energy use. (Hicks, Ward and Lester 2013)

The final version of the National Curriculum strengthened the coverage of climate change in response to these criticisms.

As well as textbooks, the teachers we spoke to also referenced the websites of NASA, New Scientist ${ }^{4}$ and the Center for Climate and Energy Solutions. We investigated the sources for these materials, and where possible, identified where these, in turn, drew information. We found that the NASA website tends to cite texts similar to those which make up one of our other corpora, consisting of policy documents. These include the Intergovernmental Panel on Climate Change (IPCC), whose reports in turn draw on academic texts. As the IPCC home page states:

Assessments of climate change by the IPCC, drawing on the work of hundreds of scientists from all over the world, enable policymakers at all levels of government to take sound, evidence-based decisions. (https://www.ipcc.ch)

By and large, the New Scientist cites peer reviewed journal research articles, which are rewritten for a popular audience. It is common for a New Scientist article to draw on two or three related research articles, and to include quotations from a brief interview with one of the research team. The Center for Climate and Energy Solutions is a think-tank describing

\footnotetext{
${ }^{4}$ The New Scientist is a popular weekly magazine covering topics of current scientific interest, aimed at an educated but not specialist readership.
} 
itself as "an independent, nonpartisan, nonprofit organisation working to forge practical solutions to climate change" (https://www.c2es.org/about/). The website contains blogposts on topics such as 'Extreme weather', which are written by members of groups of experts in areas of relevance to climate change such as public policy, environmental law, carbon capture, and personal carbon footprint. While these may be based on academic sources, they tend not to have references.

The students who we interviewed told us that they had learned about climate change at school primarily in Geography lessons, but also in Science. This is consistent with the specifications for Geography and for the three sciences in the National Curriculum for England and Wales, followed by all of their schools. They also told us that they used, or would use, websites, which they tended not to specify; the only websites named were $B B C$ Bitesize and Wikipedia. BBC Bitesize is designed to support school students with study and examinations, and is closely linked to curricula. It refers students to additional resources, such as, for climate change, the Royal Society of Chemistry, but does not cite sources. As is well-known, Wikipedia is sourced from a varied range of texts; the entry for Climate Change references a number of scientific research articles.

Based on the above data, we mapped broad patterns of knowledge transmission between different users and text-types as shown in Figure 1.

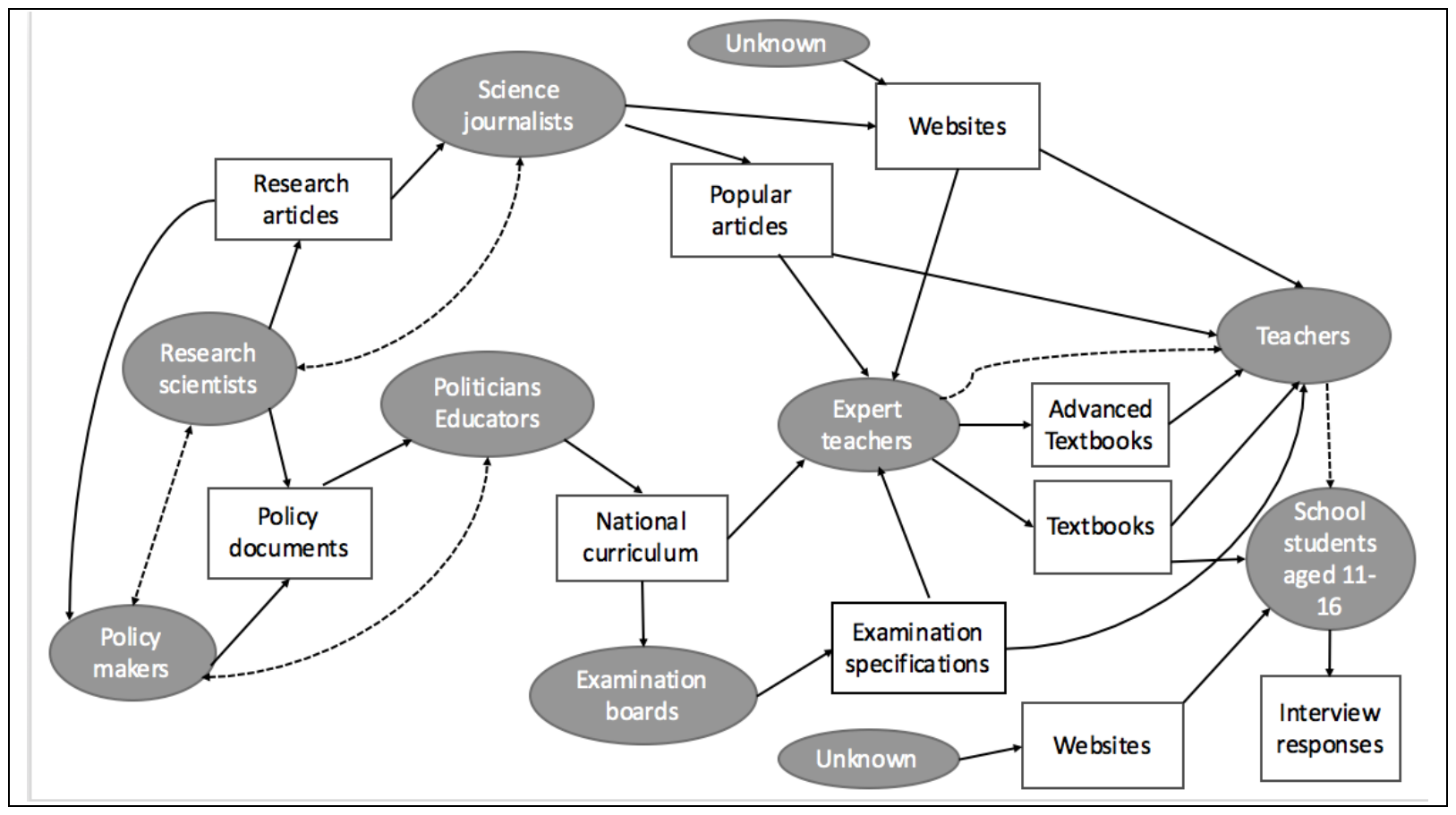

Figure 1 The communication of climate science

Text types are represented with rectangles, while groups of people are represented by ovals. The figure attempts to capture the relationships between the main groups of texts produced on the topic of climate science, how these are translated and recontextualised, 
and the groups of people that mediate this. Arrows from groups of people to text types indicate that the people author the texts. Arrows from text types to people indicate that the people are informed by them. Using a translation perspective, we can see some groups of people as 'translators'; for instance, expert teachers are informed by popular articles, websites, the national curriculum and examination specifications, and 'translate' these into advanced textbooks and textbooks. Science journalists 'translate' research articles into popular articles. Dotted lines indicate communication directly from people to people, unmediated by text. The texts produced are naturally occurring, with the exception, of course, of the student interview responses, which were elicited for this research.

We are treating the texts labelled 'Research articles' as the primary source of knowledge, and the figure can be seen as tracing this through to young people's understandings, evidenced through their interview responses. It is widely understood that research findings cannot be communicated without mediation to the non-scientific public, especially young people, because of the level of knowledge needed to interpret them; nonetheless, we did not expect the lines of communication to be so complex and indirect.

To answer our second and third research questions, we conducted qualitative and quantitative analyses of the texts comprising our corpora. Here, we report two language analyses. The first is a qualitative comparative analysis of a New Scientist article from our data, with its source, a research article. The second is a corpus study comparing metaphor use in the corpora representing teachers' sources, the sources used by students, and the student interviews.

\section{Analysis 2: Metaphor translation from academic to popular science writing}

In this section, we take a qualitative approach to the comparative analysis of metaphor use in two texts: an article from the general-audience science magazine New Scientist, 'Megafauna extinction: DNA evidence pins blame on climate change' (Slezak 2015), which was included in our Teacher Sources Corpus; and a specialist article from the journal Science which the New Scientist article is explicitly based on: 'Abrupt warming events drove Late Pleistocene Holarctic megafaunal turnover' (Cooper et al. 2015).

From the perspective adopted in this study, the author of the New Scientist article translates the contents of the Science paper for the benefit of an educated but nonacademic audience, including teachers such as the ones we interviewed. In turn, articles such as the one in question are one of the sources of scientific knowledge that teachers translate via their pedagogic practice (including teaching materials) for the benefit of their students (see Figure 1).

The topic of the two articles is a very particular aspect of the history of climate change, i.e. new findings concerning the causes of the extinction of some species of large animals (known as 'megafauna') in the Late Pleistocene period, between approximately 110,000 and 11,650 years ago. While it was previously thought that megafauna extinctions were caused by the hunting activities of humans, the Science article suggests that (non-anthropogenic) climate change may instead be responsible. New evidence on correlations between patterns of extinction and patterns of climate change shows that periods of warming in particular 
may have caused the disappearance of several megafauna species. Within this new explanation, humans have a much smaller influence: they made it difficult, through their settlements and activities, for some species of animals to relocate in order to survive during periods of rising temperatures.

We applied to each article a well-established approach to metaphor identification in language (Pragglejaz Group 2007, Steen et al. 2010), and then compared the use of metaphor across the two articles. Not surprisingly, while both articles employed a range of metaphors, there were differences in what metaphors were used and for what purpose. Here we focus on just two contrasts that can be usefully seen as examples of the kind of intralingual translation that the author of the New Scientist article engages in.

\section{A metaphor for alternative scientific explanations}

The first example concerns the way in which each text describes the existence of alternative explanations for megafauna extinctions in the scientific literature. The Science article refers to such disagreements non-metaphorically, via expressions such as 'debate', 'argument' and 'contested', as in the extract below:

Traditionally, a key argument against the potential role of climate-change impacts has been the paucity of identified extinction events during either previous glacial cycles or the many well defined [...]. (Cooper et al. 2015: 602)

While the use of the preposition 'against' following 'argument' can be described as metaphorical, the noun itself is used in its literal sense, and the metaphoricity of the preposition is highly conventionalised.

In contrast, the New Scientist article adopts an overarching Trial metaphor for different possible explanations of megafauna extinctions. The notion of 'blame' is first introduced in relation to alternative causes of extinction in the sub-title ('DNA evidence pins blame on climate change') and in the first paragraph ('it suggests that humans are not to blame'). The second paragraph develops the idea of blame into an explicit metaphorical 'trial' involving human beings as defendants:

Ever since a giant sloth was uncovered more than 200 years ago, hinting at the former presence of a menagerie of prehistoric giant mammals - the "megafauna" humans have been on trial for their extinction. And the prosecution's case has been strong.

A few paragraphs later, following a quote from Alan Cooper (the lead author of the Science article), climate change is presented as 'the real culprit' and the evidence provided by Cooper and colleagues is described as 'punch[ing] a hole in a key argument of the prosecution' (involving a further set of metaphors, which cannot be discussed here for reasons of space). In the rest of the article, the possibility that humans might still have played a role in extinctions is presented as Cooper 'not letting humans off entirely', while the claim by another scientist that humans had a greater influence than suggested in the Science article is described as 'the prosecution [...] not giving up'. This Trial metaphor is 
supported by two further linguistic and textual phenomena: first, the fact that the word 'evidence' (used in both texts) can be applied both to the context of scientific research and to that of court cases; and, second, the fact that the New Scientist article repeatedly personifies climate change as a potential 'killer' of animals, where the Science article uses the conventional technical metaphor of different possible 'drivers' of extinction.

Overall, the Trial metaphor in the New Scientist article can be described as a case of intralingual translation where non-metaphorical expressions in the source text are rendered via metaphorical expressions in the target text, or, more precisely, via a metaphorical pattern throughout the text that draws from a single scenario. As we have shown, the Trial metaphor is non-conventional in this context, and provides drama, vividness and humour to the idea that there are possible different explanations for megafauna extinctions. As such, the introduction of this metaphor reflects the need for popular science articles to attract and entertain their audiences in a way that academic articles do not. At the same time, however, the Trial metaphor also contributes to a greater ambivalence in the New Scientist article with respect to the implications of the new evidence provided in the Science article. While Cooper et al. state that this new evidence leaves little doubt as to the main cause of megafauna extinctions, the New Scientist article gives more emphasis to an ongoing debate involving different explanations. Indeed, there is no conclusion to the metaphorical trial in the target text.

\section{Metaphors for (the provision of) evidence}

Our second example of contrast between the two articles concerns the use of metaphor in reference to evidence for claims about the causes of megafauna extinctions, and/or the process of providing such evidence.

Much of the Science article revolves around the authors' visual representation of information about the two phenomena in question (patterns of megafaunal extinctions and patterns of changes in climate) over the relevant period of time. The correlation between the two patterns is not just shown numerically but visually, by means of a figure which involves a number of visual metaphors (Figure 2). 


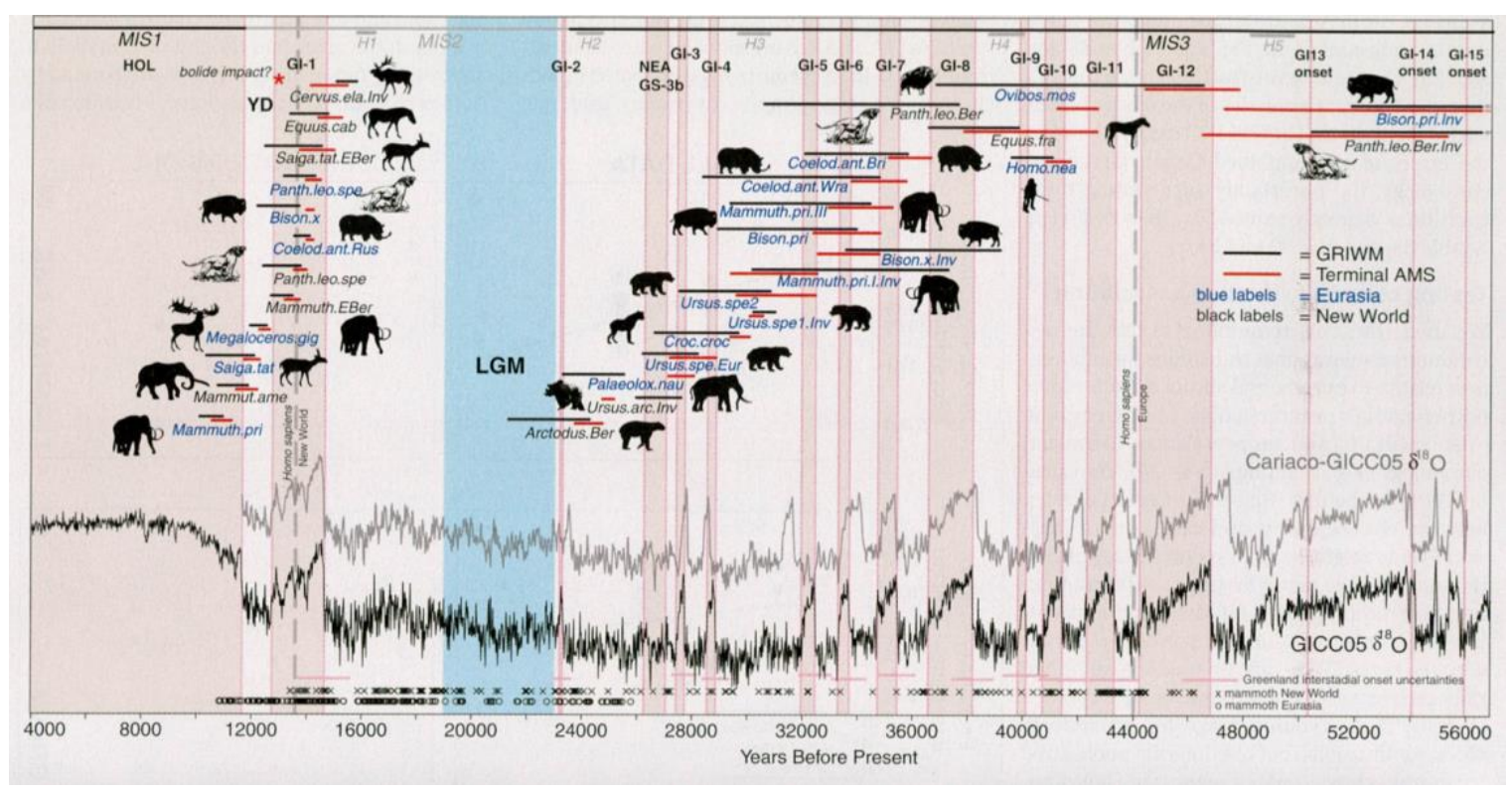

Figure 2 (Cooper et al. 2015: 603)

Broadly speaking, these metaphors are highly conventional: changes in temperature are shown as lines that join points on a vertical axis where a higher position represents a higher temperature measurement (cf. the conventional conceptual metaphor MORE IS UP); and the passing of time is represented by means of imaginary movement from left to right on a horizontal axis. In addition, Cooper et al. use some technical metaphors to refer to sections of the visual representations, such as 'asymmetrical saw-tooth pattern' and 'tie points':

The millennial length D-O events can be bundled into semi-regular cooling cycles with an asymmetrical saw-tooth pattern [...] (p. 602)

One such approach is to use the abrupt shifts at the onset of D-O warming as tiepoints to correlate across multiple climate records. (p. 603)

Deignan (2017) discusses the 'saw-tooth' metaphor, noting that corpus evidence shows it to be conventionalised in the genre of scientific research articles. She identifies a number of other conventionalised metaphorical expressions related to the appearance of a graph, including 'curve', 'steep', 'falling' and 'trajectory'. These metaphors rely on a visual similarity between a line on a graph with concrete objects, such as a saw, or movements, such as rising and falling. Several stages of transference are involved in entities such as increases or decreases in the volume of ice, or the number of species increasing or decreasing; this is represented on a graph via lines that join points on a vertical axis, using the MORE IS UP metaphor. The pattern of the line on the graph is then related to an object that it visually resembles, such as the teeth of a saw (where 'teeth' is of course itself a conventionalised metaphorical expression based on a similarity between the sharp end of the blade and human or animal teeth). 'Tie-points' similarly involves several stages of transference from the concrete meaning of physically tying something in place to its conventionalised scientific meaning of a common feature in two images that can be used as a reference point. While the concrete meanings of these figurative terms are within most speakers' experience, the 
precise reference and relevance in context may not be immediately accessible outside the expert discourse community addressed by the article.

In contrast, the New Scientist is not accompanied by figures or graphs, but rather by a photographic image of a natural environment with no living creatures within it, standing metonymically for the extinction of species. Therefore, both the visual and verbal metaphors we have just described are omitted. Nonetheless, several conventional metaphorical expressions are used to describe what the scientists are doing in terms of producing visual representations, or 'pictures':

New forensic DNA evidence is painting a detailed picture of the death of the world's megafauna.

Pulling everything together, the team was able to draw a picture that shows exactly what the climate was doing when various megafauna species vanished over the past 60,000 years. And a pattern emerges.

These are convention instantiations of the well-known KNOWING IS SEEING mapping (Deignan and Cameron, 2013).

In addition, the process of visually correlating patterns of extinction and patterns of temperature changes is described as a metaphorical 'matching' - an expression not used in the Science article:

Cooper and colleagues have simultaneously produced an unprecedentedly accurate map and timeline of changes in megafauna populations around Eurasia and North America, and precisely matched that timeline up with ancient climate records.

Finally, the expression 'uptick' is used to suggest a sudden increase in extinctions:

There was an uptick in extinctions at the end of the last ice age when, famously, the woolly mammoth met its maker.

This metaphor is similar to 'saw-tooth' and 'tie-point' in that it conveys verbally a shapebased similarity between a potential visual representation of an increase and a graphological mark. However, it is not part of the specialist technical register of academic science writing.

In this respect, the translation process involves a move from multimodal to monomodal (i.e. verbal) representations of the evidence for the new claims about the causes of megafaunal extinctions. As a consequence, the target text omits both visual and verbal technical metaphors from the original, but nonetheless describes (the provision of) evidence in terms of the process and product of visual representation. This involves both highly conventional metaphorical expressions (e.g. 'paint a picture') and less conventional but nonetheless nontechnical metaphors (e.g. 'uptick'). The result is that the readers of the New Scientist article are told about the new evidence that has been provided, whereas the readers of the Science article are shown the evidence, or at least a summary of it. Overall, the 'translation' 
involves a move from technical to informal metaphors, where the former are limited to a restricted lexical set shared by the expert discourse community, while the latter are potentially more varied in terms of lexical realisations, and conventional among most speakers of English.

\section{Analysis 3: Metaphor translation across Teacher Sources, Textbooks, Websites and Interviews}

The third study that we report here is a four-way comparison across the following corpora: Teacher Sources, Textbooks, Websites and Student Interviews. As we explained earlier, the first three corpora represent the kinds of texts that inform students, sometimes directly and sometimes through the mediation of teachers (cf. Figure 1). The last corpus, Interviews, reflects students' understandings of this material. These relationships do not involve direct intralingual translation from source to target texts as with the analysis in the previous section. Nonetheless, there is a relationship of translation at the genre level, and some interesting issues arise when the 'same' metaphor (e.g. 'greenhouse') is used differently in texts that are arguably linked via a genre-level relationship of translation.

In order to identify the most frequent domain specific metaphors and similes in each corpus, we used the Word List feature in the online corpus software Sketch Engine (Kilgarriff et al, 2014) to list lemmas in each corpus in order of frequency. As a result of our interest in domain specific meanings, we did not analyse grammatical words, as previous studies have suggested that they tend to have general metaphorical uses, which apply across genres and domains (Kimmel 2012). The focus on domain specific uses also led to the exclusion of some other frequent words: 'way' is a very frequent conventional metaphorical expression in our texts, but Stubbs (2009) shows that it occurs frequently across many discourse types, in part due to its frequency in fixed expressions such as 'the other way around' and 'only one way to find out' (Stubbs 2009: 122). From the remaining lemmas, we used concordance data to identify typical metaphorical meanings and their context (Pragglejaz 2007, Steen et al. 2010).

The Interviews corpus is relatively small $(87,888$ words), which meant that we could identify all metaphorically used words. We then compared the use of the same and related metaphors in the other three corpora. We wanted to find out how the students had reused the metaphors that they had encountered from teachers and in their reading of textbooks and outside school, and, as far as possible, what they had understood by these. Table 1 shows the five most frequent figuratively used lemmas in the Interviews corpus. With figurative uses, we included related uses such as comparisons or explanations of the figurative use.

\begin{tabular}{|l|l|l|l|l|l|}
\hline rank & lemma & $\begin{array}{l}\text { Figurative and } \\
\text { related use: } \\
\text { raw frequency }\end{array}$ & $\begin{array}{l}\text { Figurative and } \\
\text { related use: } \\
\text { per million tokens }\end{array}$ & $\begin{array}{l}\text { Other use: } \\
\text { raw frequency }\end{array}$ & $\begin{array}{l}\text { total uses of } \\
\text { lemma }\end{array}$ \\
\hline 1 & go & 388 & 4410.1 & 112 & 500 \\
\hline 2 & greenhouse & 233 & 2651.1 & - & 233 \\
\hline 3 & $\begin{array}{l}\text { Cap (in 'ice } \\
\text { cap') }\end{array}$ & 94 & 1069 & - & 94 \\
\hline 4 & release & 89 & 1012.1 & - & 89 \\
\hline 4 & trap & 89 & 1012.1 & - & 89 \\
\hline
\end{tabular}


Table 1 - The five most frequent metaphorically-used lemmas in the Interviews corpus

We now focus specifically on talk and writing in the corpora involving the term 'greenhouse', central in texts on climate change. As indicated, in the Interviews corpus 'greenhouse' is the second most frequent lemma with a figurative or related meaning. ('Go', the most frequent, is polysemous, sometimes being used to mean 'die', sometimes 'disappear', and sometimes referring to changes in temperature or other measures. Each individual figurative meaning of 'go' is less frequent than 'greenhouse', which does not display polysemy in the same way.)

The frequencies of 'greenhouse' in each of the four corpora, and relative to other figuratively used lemmas in those corpora, are shown in Table 2.

\begin{tabular}{|l|l|l|l|}
\hline Corpus & Raw frequency & Per million words & $\begin{array}{l}\text { Ranking (of figuratively used } \\
\text { lemmas in corpus) }\end{array}$ \\
\hline Interviews & 233 & 2651.1 & 2 \\
\hline Textbooks & 145 & 6604.7 & 1 \\
\hline Websites & 420 & 2230.7 & 1 \\
\hline Teacher Sources & 160 & 2983.6 & 1 \\
\hline
\end{tabular}

Table 2 - 'Greenhouse' in Interviews, Textbooks, Websites and Teacher Sources corpora

Our previous studies of academic and policy corpora (Deignan, Semino and Paul 2017, Deignan 2017) had shown that 'greenhouse' has a purely technical meaning for scientists, with little or no involvement of the literal meaning. In addition, in these corpora 'greenhouse' is used almost without exception as a noun modifier in noun groups, predominantly 'greenhouse gas(es)', 'greenhouse emission(s)' and 'greenhouse effect'. These corpora represent the source knowledge that is recontextualised, or translated, into the texts represented in the other corpora, so we regarded this as the base meaning of 'greenhouse' in climate science. In the four corpora that we consider here, however, there was greater lexicogrammatical variation, with a substantial minority of uses of 'greenhouse' as a free-standing noun (e.g. in similes such as 'like a greenhouse'), as shown in Table 3.

\begin{tabular}{|l|l|l|l|l|}
\hline & Raw frequency & $\begin{array}{l}\text { Use as noun } \\
\text { modifier }\end{array}$ & $\begin{array}{l}\text { Use as freestanding } \\
\text { noun }\end{array}$ & $\begin{array}{l}\text { Freestanding uses as } \\
\% \text { of total }\end{array}$ \\
\hline Interviews & 233 & 143 & 90 & $38.6 \%$ \\
\hline Textbooks & 145 & 131 & 14 & $9.6 \%$ \\
\hline Websites & 420 & 382 & 38 & $9 \%$ \\
\hline Teacher Sources & 160 & 154 & 6 & $3.75 \%$ \\
\hline
\end{tabular}

Table 3 - Lexicogrammatical patterns of 'greenhouse' in four corpora

We now discuss some of the citations qualitatively, beginning with the corpus that has, numerically speaking, the closest uses to the academic and policy uses, Teacher Sources. Here, 'greenhouse' is a noun modifier in $96.25 \%$ of citations. The noun most frequently modified is 'gas(es)', followed by 'effect'. In the six citations where 'greenhouse' is freestanding, three refer to the world as a greenhouse, as follows:

Human activities are changing the natural greenhouse. 
These are all from the same source, the NASA website, and two are within a sentence of each other. In the other three freestanding citations, 'greenhouse' is part of a comparison or simile. Two of these are from Advanced textbooks, as in:

In Figure 4.63 you can see how this is similar to the way that glass traps energy in a greenhouse.

The Textbooks and Websites corpora have a similar proportion of freestanding uses of 'greenhouse', though numbers are too low to state categorically that this is representative of the genres more widely. Again, these are split between simile and more expanded explanations in which the literal meaning of 'greenhouse' is actively used to explain the role of greenhouse gases in the warming of the earth's atmosphere. The following example is from the Textbooks corpus:

Greenhouse effect: A greenhouse heats up because it lets light in and uses it to cause heating. Heat is being trapped in the Earth's atmosphere, like a greenhouse. Greenhouse gases: Some gases trap energy in the atmosphere like the glass of a greenhouse traps energy.

The following example is from the Website corpus:

So during the daylight hours, it gets warmer and warmer inside a greenhouse, and stays pretty warm at night too. Earth's atmosphere does the same thing as the greenhouse. Gases in the atmosphere such as carbon dioxide do what the roof of a greenhouse does.

In the freestanding citations across all the above corpora, it is common for there to be references to the physical structure of a literal greenhouse, and particularly to the glass. The lemma 'glass' itself occurs just twice in the Teacher Source corpus but 17 times in the Website corpus (90.3 per million words), and 11 times in the Textbook corpus (501 per million words). In contrast, 'glass' is found only once in our Academic corpus, describing glass fibers. The following citations are typical:

Like the glass in a greenhouse, the gases stop energy escaping. (Textbooks)

Certain gases in the atmosphere act like the glass in a greenhouse. (Websites)

In the student Interviews corpus, 'greenhouse' is a freestanding noun for a significant proportion of citations (38.6\%). 'Glass' occurs 16 times (182 per million words). Notable here are citations in which there seems to be ambivalence between literal and figurative meanings:

Like in greenhouses, they trap heat in for plants to stay warmer and all that, and that's happening to the earth. The earth is like the plant and the CO2 is making like a glass shelter around it and it's trapping heat in. 
It's like the earth is covered in like lots of glass panels but we just can't see them cos the sun's projecting into them.

This focus on glass may suggest that students think that greenhouse gases form a layer around the earth's atmosphere, and that this is what is causing problematic levels of global warming. This is inconsistent, however, with expert explanations of the phenomenon, where the actual physical structure of greenhouses is not relevant.

Overall, 'greenhouse' is self-evidently a central term in the field-some textbook chapters are entitled 'The Greenhouse Effect' - and might therefore be atypical. However, our analyses of other frequent metaphors, such as 'release', 'trap' and 'lock', showed similar behaviour, that is, a limited and highly specific technical meaning in the 'source' scientific texts, with looser, more varied and more explicitly and actively exploited uses in corpora of 'target' texts we have analysed (Deignan 2017, Deignan, Semino, and Paul 2017).

\section{Conclusion}

In this paper we have explored metaphor use across corpora representing education-related texts on climate change that stand in a relationship of more or less direct intralingual translation. We have suggested that school teachers act as translators of scientific knowledge for the benefit of their students, but that they generally do not use scientific articles directly as source texts in this process. Rather, there is a complex web of relationships among the people and genres than influence the knowledge that secondary school students may develop on crucial topics such as climate change (cf. Research Question 1). Seeing the processes involved as a type of intralingual translation foregrounds the challenges involved in reading and writing for audiences with different amounts of expertise, even when operating within the same language.

We have also compared in detail the uses and functions of metaphors in texts that we have described as standing in a relationship of intralingual translation at the text level (the articles from New Scientist and Science) and at the genre level (the four corpora in the previous section) (cf. Research Questions 2 and 3). We have identified some strategies of metaphor translation that have not been discussed in the literature on interlingual translation, such as the move from multimodal to monomodal metaphors. More specifically, we have pointed out that the use of what appears to be the 'same' metaphor across genres (e.g. 'greenhouse') often involves considerable changes in lexicogrammatical patterns (e.g. noun premodifier vs. self-standing noun), manifestation of metaphoricity (e.g. metaphorical expression vs. simile) and degree of exploitation of the literal meaning of the term, with consequences for the use of related vocabulary (e.g. 'glass').

The differences we have pointed out highlight the usefulness of metaphor as a rhetorical and pedagogic tool, but also show that changes in metaphor use can lead to different understandings, even when the same term is involved (e.g. 'greenhouse' and the actual presence of a solid layer around the earth's atmosphere). In this respect, applying the concepts of translation and translators to the processes and people involved in communication about science can contribute to raising awareness of the challenges and 
implications of the linguistic and textual choices involved, particularly with respect to metaphor.

\section{References}

Al-Hasnawi, Ali. 2007. "A cognitive approach to translating metaphors." Translation Journal 11(3).

Barton, David. 2007. Literacy: An Introduction to the Written Language. Oxford: WileyBlackwell.

Brown, Theodore L. 2003. Making Truth: Metaphor in Science. Urbana and Chicago: University of Illinois Press

Cameron, Lynne, 2003. Metaphor in Educational Discourse. London: Continuum.

Christidou, Vasilia, Costas Dimopoulos, and Valisis Koulaidis, 2004. "Constructing social representations of science and technology: the role of metaphors in the press and popular science magazines." Public Understanding of Science 13: 347- 362.

Cooper, Alan, Chris Turney, Konrad A. Hughen, Barry W. Brook, H. Gregory McDonald, and Corey J.A. Bradshaw. 2015. "Abrupt warming events drove Late Pleistocene Holarctic megafaunal turnover." Science. 349 (6248): 602- 606.

Deignan, Alice. 2017. "Metaphor in texts about climate change." Ibérica 34: 45-66.

Deignan, Alice and Lynne Cameron. 2013. "A re-examination of understanding is seeing." Cognitive Semiotics 5(2): 220-243.

Deignan, Alice, Jeannette Littlemore, and Elena Semino. 2013. Figurative Language, Genre and Register. Cambridge, Cambridge University Press.

Deignan, Alice, Elena Semino, and Shirley-Anne Paul. 2017. "Metaphors of climate science in three genres: Research articles, educational texts, and secondary school student talk." Applied Linguistics. 1-26.

Department for Education. 2013. Reform of the national curriculum in England. London: Department for Education.

DiGiuseppe, Maurice. 2014. "Representing Nature of Science in a science textbook: Exploring author- editor- publisher interactions." International Journal of Science Education 36(7): 1061- 1082.

Hicks, Naomi, Bob Ward, and Sarah Lester. 2013. Climate Change in the National Curriculum: Submission to a consultation by the Department for Education. London: Grantham Research Institute on Climate Change and the Environment.

Incelli, Ersilia. 2018. "Popularising the Higgs boson: A corpus-assisted approach to reporting scientific discovery in online media." Corpora 13(2): 169-203.

Kilgarriff, Adam, Vít Baisa, Jan Bŭsta, Miloš Jacubíček, Vojtěch Kovář, Jan Michelfeit, Pavel Rychlý, and Vít Suchomel. 2014. "The Sketchengine, ten years on." Lexicography 1: 736.

Kimmel, Michael. 2012. "Optimizing the analysis of metaphor in discourse: How to make the most of qualitative software and find a good research design." Review of Cognitive Linguistics 10(1): 1-48.

Knudsen, Susanne. 2003. "Scientific metaphors going public." Journal of Pragmatics 35: 1247-1263.

Knudsen, Susanne. 2005. "Communicating novel and conventional scientific metaphors: a study of the development of the metaphor of genetic code." Public Understanding of Science 14: 373-392. 
Kövecses, Zoltán. 2005. Metaphor in Culture: Universality and Variation. Cambridge: Cambridge University Press.

Krein-Kühle, Monika. 2011. "Register shifts in scientific and technical translation." The Translator 17(2): 391-413.

Lakoff, George and Mark Johnson. 1980. Metaphors We Live By. Chicago: University of Chicago Press.

Liao, Min-Hsiu. 2011. "Interaction in the genre of popular science: Writer, translator and reader." The Translator 17(2): 349-368.

Lombardi, Doug, Carol B. Brandt, Elliot S. Bickel, and Colin Burg. 2016. "Students' evaluations about climate change." International Journal of Science Education 38(8): 1392-1414.

Newmark, Peter, 1988. A Textbook of Translation. London: Prentice Hall.

Pragglejaz Group. 2007. "MIP: A method for identifying metaphorically used words in discourse." Metaphor and Symbol 22(1): 1-39.

Pramling, Niklas, and Roger Säljö. 2007. "Scientific knowledge, popularisation, and the use of metaphors: Modern genetics in popular science magazines." Scandinavian Journal of Educational Research 51(3): 275-295.

Rodríguez Márquez, Maria de Montserrat. 2010. "Patterns of translation in annual reports in American English and Mexican Spanish." PhD diss., University of Surrey.

Schaeffner, Christina. 2017. "Metaphor in Translation." In The Routledge Handbook of Metaphor and Language, edited by Elena Semino and Zsófia Demjén, 247- 262. London: Routledge.

Semino, Elena, Alice Deignan, and Jeannette Littlemore. 2013. "Metaphor, genre and recontextualisation." Metaphor and Symbol 28: 41-59.

Shuttleworth, Mark. 2011. "Translational behaviour at the frontiers of scientific knowledge." The Translator 17(2): 301-323.

Slezak, Michael. 2015. "Megafaunal extinction: DNA evidence pins blame on climate change." New Scientist 3032.

Steen, Gerard, Aletta Dorst, J. Berenike Herrmann, Anna Kaal, Tina Krennmayr, and Trijntje Pasma. 2010. A Method for Linguistic Metaphor Identification. Amsterdam: John Benjamins.

Stubbs, Michael. 2009. "The search for units of meaning: Sinclair on empirical semantics." Applied Linguistics 30(1): 115-137.

Swales, John. 1990. Genre Analysis: English in Academic and Research Settings. Cambridge: Cambridge University Press.

Tasquier, Guilia, Olivia Levrini, and Justin Dillon. 2016. “Exploring students' epistemological knowledge of models and modelling in science: results from a teaching/ learning experience on climate change." International Journal of Science Education 38: 539563.

Toury, Gideon, ed. 1995. Descriptive Translation Studies and Beyond. Amsterdam: John Benjamins. 